\title{
Maintaining ethical standards in medical publishing
}

\author{
Robin Youngs, Guy Kenyon
}

All editors of medical journals have a duty to safeguard the integrity of the publishing process and must ensure that the articles that they publish do not infringe accepted ethical standards. It is, of course, the case that journals occasionally receive submissions the ethical standards of which raise concern, and in this respect The Journal of Laryngology \& Otology (JLO) is no exception. Deviation from such standards can take a number of forms and includes redundant or duplicate publication, unethical research, breaches of patient confidentiality, inappropriate authorship, plagiarism, and scientific fraud. The purpose of this editorial is to set out the ethical standards expected of submissions to the $J L O$ and to outline the responses that might be applied when these standards are not satisfied.

Redundant or duplicate publication is perhaps the most common ethical lapse. Indeed, the problem is estimated to apply to 8.5 per cent of articles submitted to otolaryngology journals. ${ }^{1}$ Duplicate publication occurs when two or more papers submitted for publication share the same hypothesis, data and conclusions without proper cross-referencing between the two papers. Such lapses are fairly easy to discover in the age of entities such as PubMed and Medline which make uncovering such fraud a relatively easy matter. By such methods, we were made aware last year of a manuscript, submitted to Otolaryngology - Head and Neck Surgery, which appeared to contain patient data that had been previously published in our journal. In the new manuscript, no attempt was made to cite the previous paper and a new raft of co-authors had appended their names to the existing data. As a result, it is likely that sanctions will be applied by the Otolaryngology-Head and Neck Surgery editors to the perpetrators of this attempt at deception.

Duplication is not the only sin. Authors submitting for publication papers containing original research should also ensure that the quality of the research complies with high ethical standards. In this respect, would-be authors are advised to consult 'Uniform Requirements for Manuscripts Submitted to Biomedical Journals: Writing and Editing for Biomedical Journals', which is issued by the International Committee of Medical Journal Editors ${ }^{2}$ and which contains recommendations that researchers should consider during the initial design stage of the study. Almost all research, and certainly research involving patient intervention, requires approval from a properly constituted ethical committee or ethical review board if it is to be acceptable. One of the most important areas of ethical consideration is the obtaining of informed consent from subjects participating in research, and this issue is, of course, one in which ethical committees have a vital interest. On at least two occasions in the past year, the $J L O$ has received papers documenting control groups of normal volunteers undergoing potentially harmful, invasive medical procedures without good evidence of a process of informed consent or of ethical committee approval. Authors submitting papers may in future be asked to provide documentary evidence of having obtained ethical committee approval for their work as well as including a written statement to that effect in the body of the paper.

Another area that frequently consumes editorial time is the submission of patient information that could lead to the subject being readily identified. ${ }^{3}$ Publication of any patient information usually requires informed consent - even if identifying features are removed. There are occasional exceptions to this policy, such as instances in which either the patient or the next of kin are untraceable or when there is an overriding public health concern making publication of patient information desirable. Authors submitting to otolaryngology journals should note that blacking out of the eyes of patient photographs is, in and of itself, insufficient as a protection of anonymity and that photographs such as this must also be accompanied by a signed statement from the patient giving explicit consent to the publication process.

There is no unanimity as to how medical journal editors should react when faced with lapses of ethical standards. ${ }^{4}$ Communication is vital, as some minor lapses of standards may occur as a result of a genuine misunderstanding of research methods and ethical principles; in such instances, an explanatory letter from the editor informing the authors of the shortcomings of their submission is often sufficient. It is also agreed that authors should have the opportunity to respond to such allegations. However, when serious misconduct, including blatant scientific fraud, has been uncovered, editors have a duty to pursue the case and, if necessary, impose sanctions. Authors should, of course, always be given the opportunity to respond to allegations of serious misconduct but when evidence of misconduct is proven editors will have to decide whether to inform the authors' employing authority - who may, in turn, initiate a formal investigation. Where there is no employing authority, the editors may be obliged 
instead to consider informing the relevant regulatory body, such as the General Medical Council for those practising in the United Kingdom.

A number of other sanctions are also available to editors. These include publication of an editorial giving details of the misconduct and either a formal retraction of the paper or a bar on future submissions from the authors for a specified period of time. In this regard, authors should be aware that in this electronic age medical editors are increasingly in contact with one another to discuss these and other issues. Otolaryngology journals in North America have formed a consortium to enable a unified approach to ethical misconduct, which includes limitation of author's privileges to publish in all the consortium's journals for a specified period of time. ${ }^{5}$ Authors should be aware that it is our intention, in the future, to share any such information with both the North American consortium and with our sister UK journal Clinical Otolaryngology.

The quality of papers published in the medical literature is, of course, upheld by the peer review process. In this respect, the $J L O$ is indebted to its assistant editors and reviewers, who work tirelessly through the hundreds of papers submitted each year. We acknowledge that we also make mistakes in the editorial process and, in this regard, it is important that authors have the opportunity to appeal if they consider their paper to have been harshly judged by the review process. In these cases, a letter should be sent to the editors documenting in detail the grounds for appeal; a further review of the editorial decision will then be undertaken. This will normally include an additional and independent peer review. In addition, if there is a critical response from readers to an article already published, the forum afforded by the 'Letters to the Editor' column is always available for readers' critical responses and authors' replies and explanations.

Finally, a substantial review of the $J L O$ website (www.jlo.co.uk) is currently being undertaken; the revised website will include a section explicitly stating the journal's policy regarding ethical conduct, including the responsibilities of the editorial body. We are also available to discuss these matters with authors if they wish to contact us through the editorial office.

\section{References}

1 Rosenthal EL, Masdon JL, Buckman C, Hawn D. Duplicate publications in the otolaryngology literature. Laryngoscope 2003;113:772-4

2 International Committee of Medical Journal Editors (ICMJE). Uniform requirements for manuscripts submitted to biomedical journals: writing and editing for biomedical publication. http://www.icmje.org [Accessed 25.11.2005]

3 Singer P. Consent to the publication of patient information. BMJ 2004;329:566-8

4 Smith J, Goodlee F. Investigating allegations of scientific misconduct. $B M J$ 2005;331:245-6

5 Benninger MS, Jackler RK, Johns MME, Johnson JT, Kennedy DW, Ruben RJ et al. Consortium of otolaryngology - head and neck surgery journals to collaborate in maintenance of high ethical standards. Arch Otolaryngol Head Neck Surg 2005;131:381-2 